\title{
HAIR DYE POISONING: A CASE REPORT
}

\section{T. Shankar' ${ }^{1}$, G. Raghunadh Babu², S. Ramakrishna 3 , B. Kathyayini ${ }^{4}$, A. Surekha ${ }^{5}$}

\section{HOW TO CITE THIS ARTICLE:}

T. Shankar, G. Raghunadh Babu, S. Ramakrishna, B. Kathyayini, A. Surekha. "Hair Dye Poisoning: A Case Report." Journal of Evolution of Medical and Dental Sciences 2015; Vol. 4, Issue 45, June 04; Page: 7869-7873,

DOI: $10.14260 /$ jemds/2015/1147

ABSTRACT: Super Vasmol is one of the commonly used, cheap, freely available hair dye poisoning is emerging a major cause of suicidal poisoning in India, and the hair dyes mainly contain paraphenylene diamine (PPD) and resorcinol. Acute poisoning by PPD causes characteristic sever angio-neurotic oedema of upper air way associated with a swollen, dry, hard and protruding tongue, systemic intoxication results in multisystem involvement and can cause rhabdomyolysis, acute renal failure (ARF). There is no specific antidote for PPD and treatment mainly supportive, emergency tracheostomy will help the patient to relieve the airway obstruction and reduce mortality. We report a case of suicidal ingestion of hair dye that was presented with cervico-fascial oedema later developed rhabdomyolysis and acute renal failure managed with emergency tracheostomy, systemic management and dialysis.

KEYWORDS: Acute renal failure, PPD, Rhabdomyolysis, Stridor, Tracheostomy.

INTRODUCTION: Hair dye poisoning is an uncommon form of intoxication in the western countries though it is fairly common in some parts of the world such as Africa,(1) the accidental or intentional poisoning results in systemic toxicity(2) in a dose - dependent manner.(3) Super vasmol33 is an emulsion based hair dye commonly used in India.

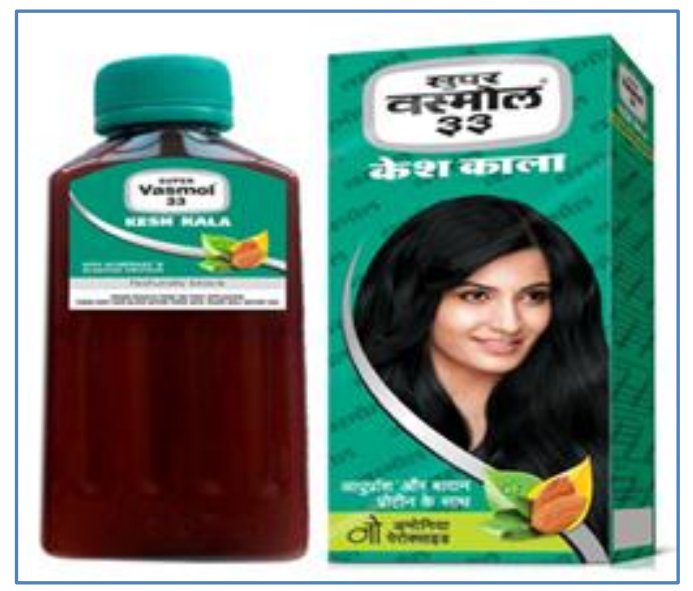

\section{Figure 1: Super Vasmol 33 Hair dye container}

The main ingredients of hair dye are,

- Para - phenylene diamine (<4\%) (PPD).

- Resorcinol.

- Propylene glycol.

- Liquid paraffin. 
- Cetostearyl alcohol.

- Sodium laurylsulfate.

- EDTA sodium.

- Herbal extracts and preservatives and perfumes.

Some of these ingredients are known toxicants with multi organ effects, while the toxicity profiles of others are not known, accidental or suicidal ingestion of the PPD causes systemic toxicity, manifested by sever oedema of neck, face and laryngeal oedema with respiratory distress, frequently requiring emergency tracheostomy,(4) and mechanical ventilation, it also causes, rhabdomyolysis and acute renal failure, culminating in death if not treated aggressively.(5)

Resorcinol is a phenolic chemical used in photography training and cosmetic (hair dye) industry, it is also a pharmaceutical agent used topically in skin diseases-resorcinol is a moderately toxic and corrosive chemical. It is known to cause eye, skin, oral and gastro intestinal injuries, systemic toxicity is manifested as vomitings, dyspnea, Hypothermia, tachycardia, profuse sweating, Hypotension and pallor.(6)

CASE REPORT: A 22 year female was brought to the emergency department of Govt. ENT Hospital, Koti, Hyderabad with a complaint of having consumed super vasmol 33 hair dye 2 hours prior to presentation, on presentation she had complaints, of respiratory distress, difficulty to open her mouth, on examination, she was found in sever stridor with swelling in the floor of the mouth, systemic examination was shows hypotension, tachycardia and profuse sweating. Emergency Tracheostomy was done to relieve the stridor. On $2^{\text {nd }}$ day she had black coloured urine and damaged liver and renal parameters.

\section{Investigations Revealed:}

1. Myoglobinuria.

2. Hyperkalemia.

3. Blood gas analysis showed - metabolic acidosis.

Treated with hemodialysis and parenteral steroids along with care of tracheostomy tube, she was improved in a week time, the tracheostomy was closed and discharged. Patient is under follow up.

DISCUSSION: Though hair dye poisoning is rare in western countries, it is common in Eastern Africa, Middle East countries and Indian subcontinent. Common hair dye ingredients used are, hydrogen peroxide, PPD, resorcinol or aminophenol. (7) But the manufacturer of Vasmol claims that no hydrogen peroxide or ammonia was added. Although there are a few studies that indicate systemic toxic effects of PPD on humans, information on the effects of resorcinol in acute poisoning after oral ingestion is limited.

Resorcinol is of moderate acute toxicity. Studies have reported rapid absorption of resorcinol from GI tract following its oral ingestion. It is rapidly metabolized and excreted death, following resorcinol ingestion is associated with, convulsions, salivation, dyspnoea, emaciation and hyperaemia of the GI tract. The lowest lethal dose (LDL) of resorcinol in humans has been reported as $29 \mathrm{mg} / \mathrm{kg}$ body wt.(8) Studies report that systemic manifestations of resorcinol poisoning may include nausea, 


\section{CASE REPORT}

dyspnea, methemoglobinemia, tachypnea, pallor and profuse sweating, with hypotension and tachycardia. Pulmonary oedema and bronchospasm may also occur. Resorcinol is also neurotoxin and its acute exposure effects range from seizures, followed by CNS depression to lethargy, coma and death.

Paraphenylene diamine (PPD) is a key ingredient of hair dyes, used for colour enhancement. Only few, studies have been done on systemic PPD poisoning. Common clinical manifestations of systemic toxicity are, cervico-fascial oedema, chocolate brown coloured urine, upper airway tract oedema, and oliguric muscular oedema shock(9) the biological results were dominated by rhabdomyolysis(10), metabolic acidosis, acute renal failure and hyperkalemia.

Among the Egyptians, there were hairdressers as early as 5000 years BC and the art of dyeing hair with vegetables dyes was known already at that time. The first artificial dye was synthesized in the laboratory in 1856, and permanent hair colorants have been in commercial use for over 100 years. Hair dyes can be divided into five categories, each with a specific composition and action mechanism; gradual hair colouring (using metallic dyes such as salts of lead, bismuth or silver), vegetable hair dyes (such as henna) temporary dyes (water-soluble dyes that withstand only one time shampooing), semi-permanent dyes (which can withstand 4-5 times shampooing) and permanent hair colours. Permanent hair colours are the most popular hair dye products. They may be further divided into oxidation hair dyes and progressive hair dyes. Oxidation hair dye products consist of $(1)$ a solution of dye intermediates, e.g., p-phenylenediamine, which form hair dyes on chemical reaction, and performed dyes, e.g., 2-nitro-p-phenylenediamine, which already are dyes and are added to achieve the intended shades, in aqueous, ammonia cal vehicle containing soap, detergents and conditioning agents; and(2) a solution of hydrogen peroxide, usually $6 \%$ in water or a cream lotion the ammonia cal dye solution and the hydrogen peroxide solution, often called the developer, are mixed shortly before application to the hair. The applied mixture causes, the hair to swell and the dye intermediates (and performed dyes) penetrate the hair shaft to some extent before they have fully reacted with each other and the hydrogen peroxide and formed the hair dye.

Progressive hair dye products contain lead acetate as the active ingredient. Lead acetate is approved as a colour additive for colouring hair on the scalp at concentrations not exceeding $0.6 \%$ $\mathrm{w} / \mathrm{v}$, calculated as metallic lead. Bismuth citrate, the other approved colour additive, is used to a much lesser extent. Progressive hair dyes change the colour of hair gradually from light straw colour to almost black by reacting with the sulphur of hair keratin as well as oxidizing on the hair surface hair dye consumption is not an uncommon means of intentional self-harm. It has been reported around the world, more so in the underdeveloped and developing countries. Case series from Khartoum and Casablanca have reported 46 cases of hair dye (paraphenylenediamine) poisoning. Paraphenylene diamine poisoning was the number one cause of poisoning in Morocco during the 1990s. Numerous case reports have been reported from India.

The characteristic triad of features encountered are early angio-neurotic oedema with strider, rhabdomyolysis with chocolate coloured urine and acute renal failure. Whenever this combination occurs in poisoning, hair dye is a strong suspect.

Kellel et al, studied 19 patients with PPD intoxication in Tunisia over a 6 year period. Clinical symptoms were dominated by cervicofacial oedema (79\%), chocolate-brown coloured urine (74\%), upper airway tract oedema (68.4\%), oliguria (36.8\%), muscular oedema (26.3\%) and shock (26.3\%). rhabdomyolysis and metabolic acidosis were seen in all the patients. ARF was seen in $47.4 \%$ and hyperkalemia $26.3 \%$ in the series by Ram et al. The incidence of ARF was $70 \%$. All had 
rhabdomyolysis. Four patients required tracheostomy and ventilator assistance. Two large series have been published from the African continent. In a11-year retrospective study of PPD poisoning reported tot eh poison control centre of Morocco, 374 cases were analysed. Rhabdomyolysis and acute renal failure were the main contributing factors for the $21 \%$ mortality. Suleiman et al., studied 150 patients who presented with PPD poisoning in Sudan over a 10-year period.

The treatment is mainly supportive and depends on clinical presentation. Antihistamines and steroids are commonly used in the management of airway oedema because of the possibility of a hypersensitivity reaction to PPD but there is no evidence to support this mode of treatment. Alkaline diuresis using isotonic saline, sodium bicarbonate, and diuretics are used in the management of myoglobinuria. There is no specific antidote for PPD, and trials of PPD removal using hemoperfusion and hemodialysis had variable results. The toxin is not dialyzable and dialysis is only supportive therapy.

CONCLUSION: Early diagnosis of rhabdomyolysis, acute renal failure and upper airway oedema, with institution of appropriate supportive management will have a better outcome in hair dye poisoning, early airway protection, alkaline diuresis and dialysis are the three management strategies helpful in this situation. Awareness about this condition is useful in early treatment and to reduce mortality. Health education to general public is helpful to avoid ingestion of hair dye poisoning.

\section{REFERENCES:}

1. Filali A, Semlali I, Ottaviano V, Furnari C, Corradini D, Soulaymani R. A retrospective study of acute systemic poisoning of paraphenylenediamine (occidental takawt in Morocco). Afr J Tradit Complement Altern Med 2006; 39: 142-9.

2. Suliman SM, Fadlalla M, Nasr Mel M, et al. Poisoning with hair-dye containing paraphylene diamine: ten year experience. Saudi J Kidney Dis Transpl 1995; 6: 286-9.

3. Kallel H, Chelly H, Dammak H, et al. Clinical manifestations of systemic paraphenylene diamine intoxication. J Nephrol 2005; 18: 308-11.

4. Singla S, Miglani S, Lal AK, Gupta P, Agarwal AK. Para-phenylenediamine (PPD) poisoning. J Acad Clin Care Med 2005; 6: 236-8.

5. Bhargava P, Matthew P. Hair dye poisoning. J Assoc Physicians India 2007; 55: 871-2.

6. Verma R, Tewari N, Jaiswal S, Rastogi V, Singh DK, Tiwari A. Fatal poisoning caused by oral ingestion of a hair dye. Internet J Emerg Intensive Care Med 2008; 11(1). See (last accessed 2 March 2010).

7. Soni SS, Nagarik AP, Dinaker M, Adikey GK, Raman A. Systemic toxicity of Paraphylene diamine. Indian J Med Sci 2009; 63: 164-6.

8. Sampathkumar K, Yesudas S. Hair dye poisoning and the developing world. J Emerg Trauma Shock 2009; 2: 129-31.

9. Yabe K. The effect of a p-phenylenediamine containing hair dye on the Ca2+ mobilization in the chemically skinned skeletal muscle of the rat. Nihon Hoigaku Zasshi 1992; 46: 132-40.

10. Huerta-Alardín AL, Varon J, Marik PE. Bench-to-bedside review: Rhabdomyolysis - an overview for clinicians. Crit Care 2005; 9: 158-69. 


\section{CASE REPORT}

\section{AUTHORS:}

1. T. Shankar

2. G. Raghunadh Babu

3. S. Ramakrishna

4. B. Kathyayini

5. A. Surekha

\section{PARTICULARS OF CONTRIBUTORS:}

1. Professor, Department of ENT, Osmania Medical College.

2. Professor, Department of ENT, Andhra Medical College, Vizag.

3. Professor \& HOD, Department of ENT, Osmania Medical College.

\section{FINANCIAL OR OTHER}

COMPETING INTERESTS: None
4. Senior Resident, Department of ENT. Osmania Medical College.

5. Resident, Department of ENT, Osmania Medical College.

\section{NAME ADDRESS EMAIL ID OF THE}

\section{CORRESPONDING AUTHOR:}

Dr. T. Shankar,

H. No. 12-5-149/6/A,

Flat No. 201, Sajjas Ambuiance,

Vijayapuri Colony, Tarnaka,

Hyderabad-17, Telangana.

E-mail: drshankar_ms@yahoo.com

Date of Submission: 12/05/2015.

Date of Peer Review: 13/05/2015.

Date of Acceptance: 28/05/2015.

Date of Publishing: 04/06/2015. 